\title{
Ethnic differences in childhood right and left cardiac structure and function assessed by cardiac magnetic resonance imaging
}

\author{
Wouter J. van Genuchten ${ }^{1,2} \cdot$ Liza Toemen $^{1,2} \cdot$ Arno A. W. Roest $^{3} \cdot$ Meike W. Vernooij $^{4} \cdot$ Romy Gaillard $^{1,2}$. \\ Willem A. Helbing ${ }^{2} \cdot$ Vincent W. V. Jaddoe ${ }^{1,2}$
}

Received: 18 June 2020 / Revised: 27 October 2020 / Accepted: 2 November 2020 / Published online: 10 November 2020

(C) The Author(s) 2020

\begin{abstract}
Ethnic differences in cardiovascular risk factors and disease are well-known and may originate in early-life. We examined the ethnic differences in cardiac structure and function in children using cardiac magnetic resonance imaging in a European migrant population, and whether any difference was explained by early life factors. We used a prospective population-based cohort study among 2317 children in Rotterdam, the Netherlands. We compared children from Dutch (73\%), Cape Verdean (3.5\%), Dutch Antillean (3.3\%), Moroccan (6.1\%), Surinamese-Creoles (3.9\%), Surinamese-Hindustani (3.4\%), and Turkish (6.4\%) background. Main outcomes were cMRI-measured cardiac structures and function. Cardiac outcomes were standardized on body surface area. Cape Verdean, Surinamese-Hindustani, and Turkish children had smaller right ventricular end-diastolic volume and left ventricular end-diastolic volume relative to their body size than Dutch children $(p<0.05)$. These results were not fully explained by fetal and childhood factors. Right ventricular ejection fraction and left ventricular ejection fraction did not differ between ethnicities after adjustment for fetal and childhood factors.

Conclusion: Right ventricular end-diastolic volume and left ventricular end-diastolic volume differ between ethnic subgroups in childhood, without affecting ejection fraction. Follow-up studies are needed to investigate whether these differences lead to ethnic differences in cardiac disease in adulthood.
\end{abstract}

What is Known:

- Ethnic differences in cardiovascular risk factors and disease are well-known and may originate in early-life.

- The prevalence of cardiovascular disease differs between ethnic groups.

What is New:

- We examined ethnic differences in left and right cardiac structure and function in children using cMRI.

- Right and left cardiac dimensions differ between ethnic groups in childhood and are only partly explained by fetal and childhood factors.

Keywords Pediatrics $\cdot$ Cardiovascular risk $\cdot$ Cardiovascular imaging $\cdot$ MRI $\cdot$ Ethnic groups

Wouter J. van Genuchten and Liza Toemen contributed equally to this work.

Communicated by Gregorio Paolo Milani

Vincent W. V. Jaddoe

v.jaddoe@erasmusmc.nl

Wouter J. van Genuchten

w.vangenuchten@erasmusmc.nl

Liza Toemen

1.toemen@erasmusmc.nl

Arno A. W. Roest

A.Roest@lumc.nl

\author{
Meike W. Vernooij \\ m.vernooij@erasmusmc.nl \\ Romy Gaillard \\ r.gaillard@erasmusmc.nl \\ Willem A. Helbing \\ w.a.helbing@erasmusmc.nl
}

Extended author information available on the last page of the article 


$\begin{array}{ll}\text { Abbreviations } \\ \text { BMI } & \text { Body mass index } \\ \text { BSA } & \text { Body surface area } \\ \text { cMRI } & \text { Cardiac magnetic resonance imaging } \\ \text { LVEF } & \text { Left ventricular ejection fraction } \\ \text { LVEDV } & \text { Left ventricular end-diastolic volume } \\ \text { LVM } & \text { Left ventricular mass } \\ \text { LMVR } & \text { Left ventricular mass to volume ratio } \\ \text { RVEF } & \text { Right ventricular ejection fraction } \\ \text { RVEDV } & \text { Right ventricular end-diastolic volume }\end{array}$

\section{Introduction}

The prevalence of cardiovascular disease differs between ethnic groups [1-4]. Studies in the USA suggest that adults from Hispanic and African American background have higher risks of cardiovascular disease than adults from European background $[1,2]$. Similarly, in the UK, cardiovascular disease risk is higher among adults from West-African and SouthAsian background than among Caucasians $[3,5]$. In the Netherlands, lower cardiovascular mortality was reported among adults from Morocco, but higher mortality was observed among the Surinamese than among native Dutch adults [5]. These possible differences are increasingly relevant with the number of migrants in Western Europe [6,7].

Differences in common risk factors for cardiovascular disease such as body mass index (BMI), blood pressure, and lipid and insulin concentrations can already be observed in childhood and track to adulthood [8-11]. We previously reported ethnic differences in common cardiovascular risk factors in childhood in the Netherlands, which were mainly explained by early life factors [10]. Although cardiac structures are independent risk factors for mortality in adults, and tend to track from childhood to adulthood, ethnic differences in cardiac structure and function have been studied less extensively $[12,13]$.

Greater left ventricular end-diastolic volume (LVEDV), left ventricular mass (LVM), and lower LV ejection fraction (LVEF) have been observed in Americans from African background than European background [14]. In the UK, adults from Indian Asian background had smaller LVEDV and LVM than those from European background [15]. Studies in children do not show consistent results [16, 17]. In childhood, lean body mass explains most of the variation in LVM and might differ between ethnicities [10, 18]. Differences in lean mass and other early life factors may influence the ethnic differences in cardiac structure. Most previous studies used echocardiography to evaluate cardiac structures. However, cardiac magnetic resonance imaging (cMRI) has been found to be more accurate and reproducible than echocardiography, and enables studies on volumes of the right side of the heart, another independent risk factor for cardiovascular mortality [19-21].
We examined ethnic differences in left and right cardiac structure and function in children using cMRI in a multi-ethnic population-based study among 2317 children in Rotterdam, the Netherlands, and examined whether any difference was explained by differences in fetal and childhood factors.

\section{Methods}

\section{Study design}

This study was embedded in the Generation R Study, a multi-ethnic population-based prospective cohort study from fetal life until young adulthood in Rotterdam, the Netherlands; we described a general power calculation in the study design paper. For the current explorative analyses, we used a minimum of 50 children per subgroup based on the data availability [22]. The study has been approved by the Medical Ethics Committee of the Erasmus University Medical Center, Rotterdam. Written informed consent was obtained from all parents of participants. At the age of 10, children underwent full-body MRI, including cMRI; because of later start of the MRI studies, not all children within the follow-up period attended the MRI center. A total of 4245 MRI scans were performed during the visit to our research center. cMRI scans were successful for 2957 children. Missing scans were mainly due to poor quality or failure of equipment. We excluded children who were part of a small ethnic group (if $n<75)(n=554)$; because they were twins ( $n$ $=71$ ); or because they were diagnosed with various cardiac abnormalities $(n=15)$. In total 2317 MRI scans were used in the analysis (Fig. 1). Non-response analyses showed that non-responders were more often boys, of non-Dutch ethnicity, and from lower income families (Supplemental Material Table S1).

\section{Ethnic background}

Ethnic background of the child was defined by the country of birth of the parents, as previously described [10, 22, 23]. We defined the following non-Dutch groups: Cape Verdean $(n=$ $85)$, Dutch Antillean $(n=79)$, Moroccan $(n=144)$, Surinamese $(n=173)$, and Turkish $(n=152)$. Because the Surinamese population consists of persons who originate from Africa (Creoles) and India (Hindustani), we further classified this group into Surinamese-Creole $(n=93)$ or SurinameseHindustani $(n=80)$ [24].

\section{Cardiac magnetic resonance imaging outcomes}

We performed cMRI using a wide-bore 3 Tesla scanner (Discovery MR 750, General Electric, Milwaukee, MI, 
Fig. 1 Flow chart of participants included in the analysis

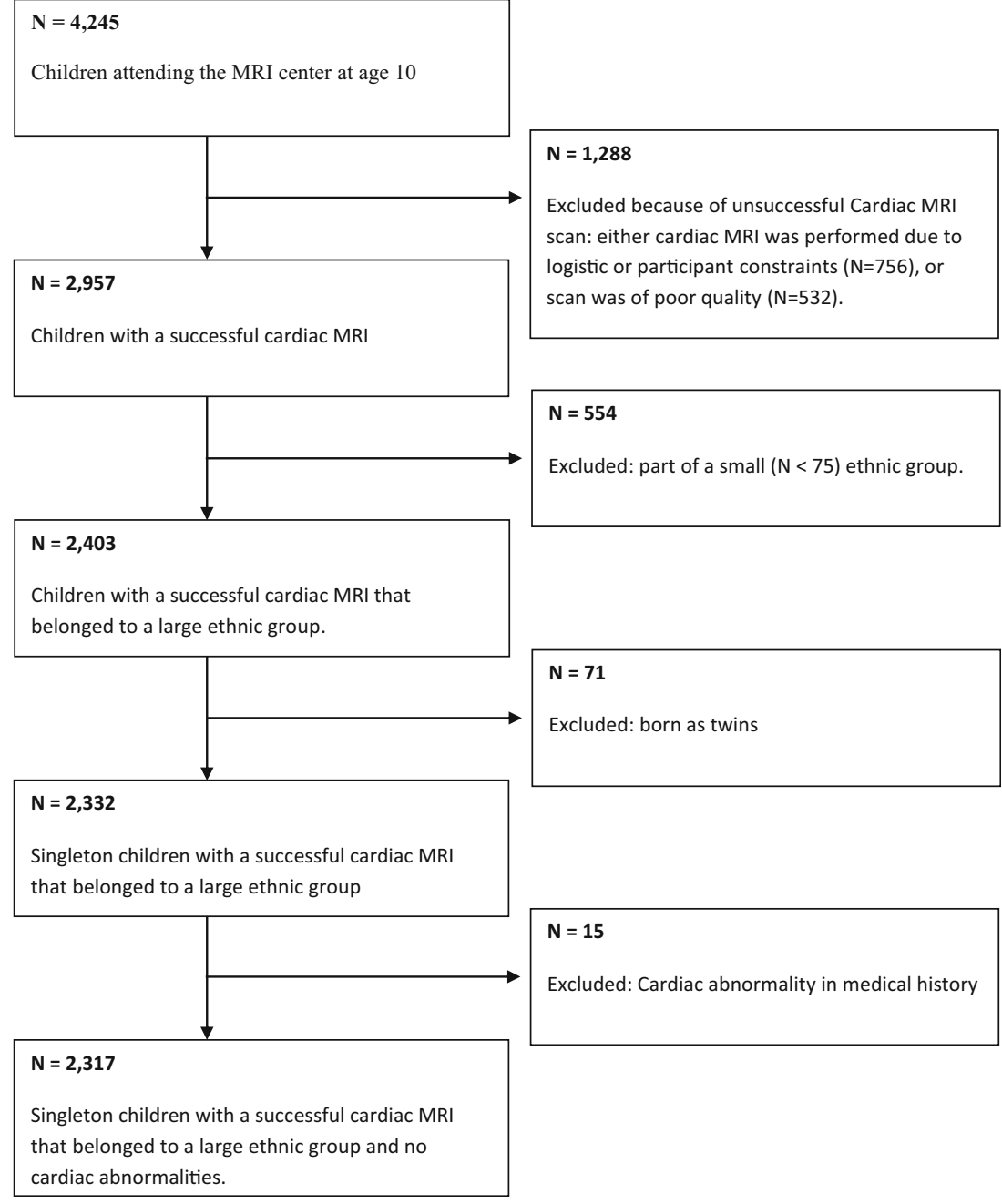

USA), as described in more detail previously [25]. Briefly, we acquired localizer images, followed by ECG gated breath-held scans lasting less than $10 \mathrm{~s}$ per breath-hold. A short-axis steady-state free precession (SSFP) cine stack was then obtained with basal slice alignment and covering the ventricles and part of the atria with contiguous 8 -mm-thick slices over several end expiration breath-holds. We used a cardiac scanning time of 12 min because of the population-based nature of this study. The scans were stored on a digital archive for post-processing. Off-line image analyses for right and left ventricular measures on the short-axis cine stack were performed by a commercial party and analyzed under supervision of an experienced radiologist (Precision Image Analysis, Kirkland, WA, USA), using Medis QMASS software (Medis, Leiden, the Netherlands). Cardiac measurements included right ventricular end-diastolic volume (RVEDV), right ventricular ejection fraction (RVEF), LVEDV, LVEF, and LVM. We calculated left ventricular mass to volume ratio (LMVR) as LVM/LVEDV.

\section{Covariates}

Information on maternal education, pre-pregnancy body mass index, gestational age, and birth weight was collected by questionnaires and medical charts. Childhood lean body mass percentage was obtained by dual-energy X-ray absorptiometry (DXA) scan (iDXA, General Electric, formerly Lunar Corp., Madison, WI). Percent lean body mass was calculated as lean mass $(\mathrm{kg}) /$ body weight $(\mathrm{kg})$. Child height and weight were used to calculate body surface area (BSA), using Haycock's formula [26]. Child systolic pressure and diastolic blood pressure were measured on the right brachial artery, using the validated automatic sphygmomanometer Accutorr Plus (Datascope Corporation, Fairfield, NJ). These measurements preceded the cMRI visit by a median of 1.1 months $(95 \%$ range 0-24.8 months).

\section{Statistical analysis}

We constructed BSA adjusted standard deviation scores for the following cardiac outcomes: RVEDV, RVEF, 
LVEDV, LVEF, and LVM, using the GAMLSS in R version 3.6.1 [27,28]. Since LMVR is not usually normalized on BSA, we created standard deviation scores (SDS) not based on BSA. We used linear regression models to assess the associations of ethnic background with RVEDV, RVEF, LVEDV, LVEF, LVM, and LMVR. The basic models were adjusted for child's age at the visit, sex, time difference between measurement of BSA and cMRI. If the basic model showed a significant difference, we additionally adjusted for a fetal model which included maternal pre-pregnancy BMI, education level, and gestational age adjusted birth weight, and a childhood model which included all previously mentioned covariates and childhood lean body mass percentage. We started with a wider range of possible covariates based on previous literature. We investigated if those covariates had an effect of $>10 \%$ in one or more ethnic groups. In the fetal and childhood, all covariates had a $>10 \%$ effect on one of the ethnic groups. Because all variables were highly correlated, adjusting for multiple testing would be too stringent; we did not adjust for multiple testing. However we depicted $p$ values as 0.05 and 0.01 level, which enables readers to interpret the significance level. To reduce potential biases related to missing data in covariates, we performed multiple imputation using the MICE packages in $\mathrm{R}(n=10)$ [29]. All the analyses were done in R 3.6.1 [27].

\section{Results}

\section{Subject characteristics}

Table 1 shows the subject characteristics. Birth weight was lower in all ethnic groups than in Dutch children, except birthweight of Moroccan children. All ethnic groups, except Moroccan and Surinamese-Hindustani, had higher childhood BSA. The lean mass percentage was lower in all ethnic minorities than in Dutch children, except for the Surinamese-Creole. Table 2 presents the observed cardiac outcomes for the total group and categorized per ethnic group, without taking body size into account. Moroccan children had smaller absolute LVEDV than Dutch children. Surinamese-Hindustani children had smaller RVEDV, LVEDV, and LVM, whereas Surinamese-Creole children had smaller LVEF than Dutch children. Turkish children had smaller RVEDV and LVEDV compared to Dutch children

\section{Ethnic background and cardiac outcomes measured by CMRI}

Table 3 shows that as compared to Dutch children, relative to their current body size, Cape Verdian children had smaller
RVEDV (difference -0.35 SDS $(95 \%$ confidence interval (CI) $-0.56,-0.15)$ ) and LVEDV (difference -0.33 SDS (95\% CI $-0.53,-0.13)$ ). Surinamese-Hindustani children had smaller RVEDV (difference - 0.51 SDS $(95 \%$ CI $0.71,-0$.$) ) and LVEDV (difference -0.57$ SDS (95\% CI $0.77,-0.37)$ ). Turkish children had smaller RVEDV (difference -0.44 SDS $(95 \%$ CI $-0.59,-0.29)$ ) and LVEDV (difference -0.38 SDS $(95 \%$ CI $-0.53,-0.23)$. After adjusting for fetal and childhood factors, the effect estimates attenuated slightly for RVEDV and LVEDV but remained significant in Cape Verdean, Surinamese-Hindustani, and Turkish children. No ethnic differences in RVEF or LVEF were observed.

The associations of ethnic background with LVM and LMVR are given in Table 4. Surinamese-Hindustani children had lower LVM (difference - 0.27SDS $(95 \%$ CI - 0.48, $0.07)$ ) and higher LMVR (difference 0.78 SDS (95\% CI 0.50 , 1.06)). These differences attenuated fully after adjusting for fetal factors.

\section{Discussion}

In this multi-ethnic population-based prospective cohort study among 10-year-old children born in the Netherlands, children from Cape Verdean, Surinamese-Hindustani, and Turkish background had smaller RVEDV and LVEDV, relative to their current BSA than Dutch children. These differences were only partly explained by fetal and childhood factors. We did not find consistent associations of ethnicity with RVEF, LVEF, LVM, or LMVR after adjusting for fetal or childhood factors.

Several studies have shown a difference in cardiovascular disease between ethnic groups [1-5]. In the Netherlands, higher cardiovascular mortality has been observed in adults of Surinamese background [5]. Adults from Moroccans background generally show lower risk of cardiovascular mortality [5]. Although self-reported cardiovascular disease was higher in adults from Turkish background, studies on cardiovascular outcomes have reported conflicting results [5,30].

In our current study, we observed lower RVEDV and LVEDV in children from Cape Verdean, SurinameseHindustani, and Turkish background, as compared to Dutch children. The differences in RVEDV and LVEDV in children from Cape Verdean, Surinamese-Hindustani, and Turkish background attenuated slightly after adjustment for fetal and childhood factors. In childhood, cardiac size is mainly determined by lean body mass [18]. Although we standardized the cardiac outcomes on BSA and adjusted for lean body mass percentage, other unaccounted factors of body size and composition might explain part of the differences in cardiac structure that we observed. Also, it is known that well-trained athletes have a larger LVEDV 


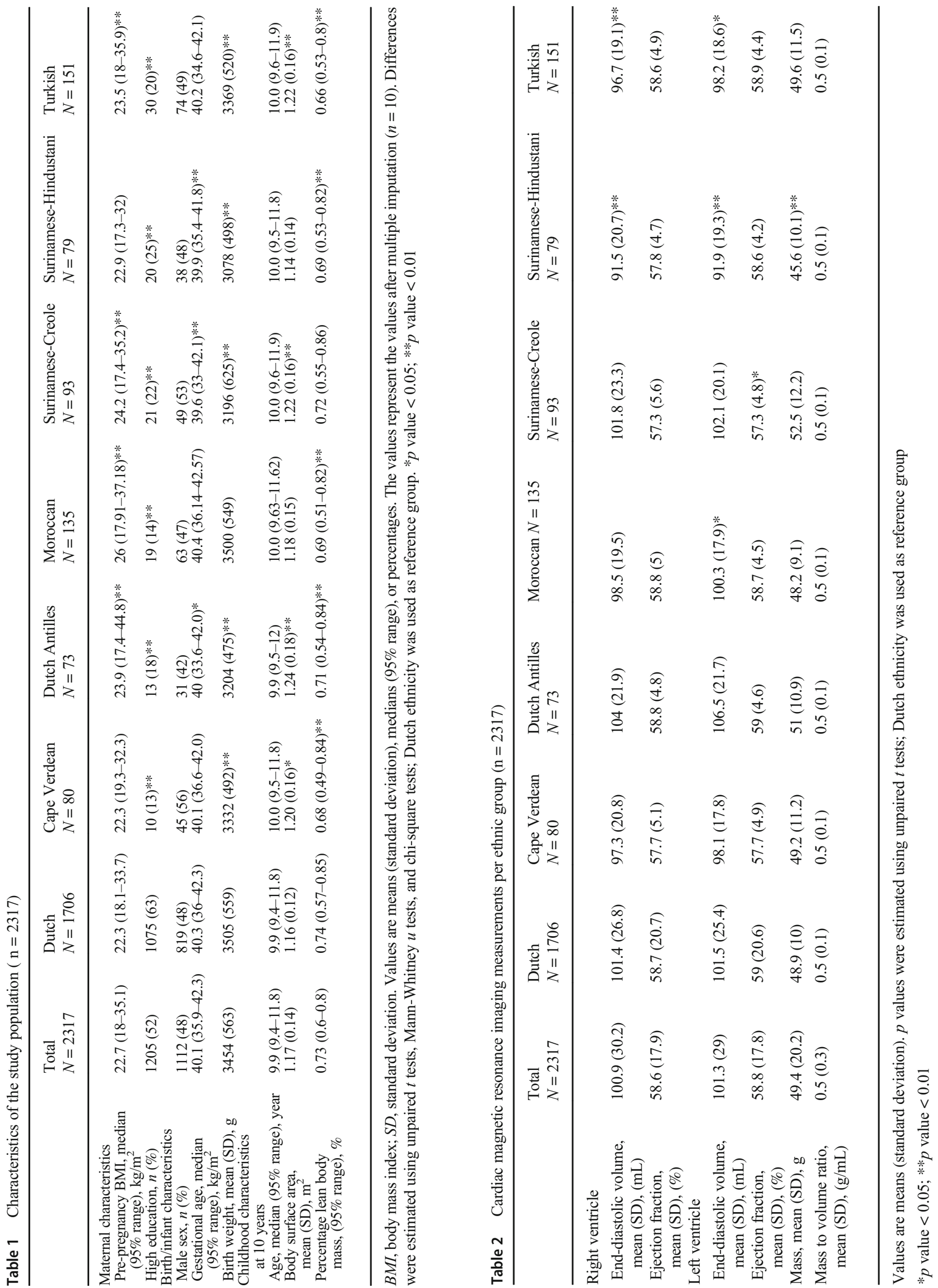




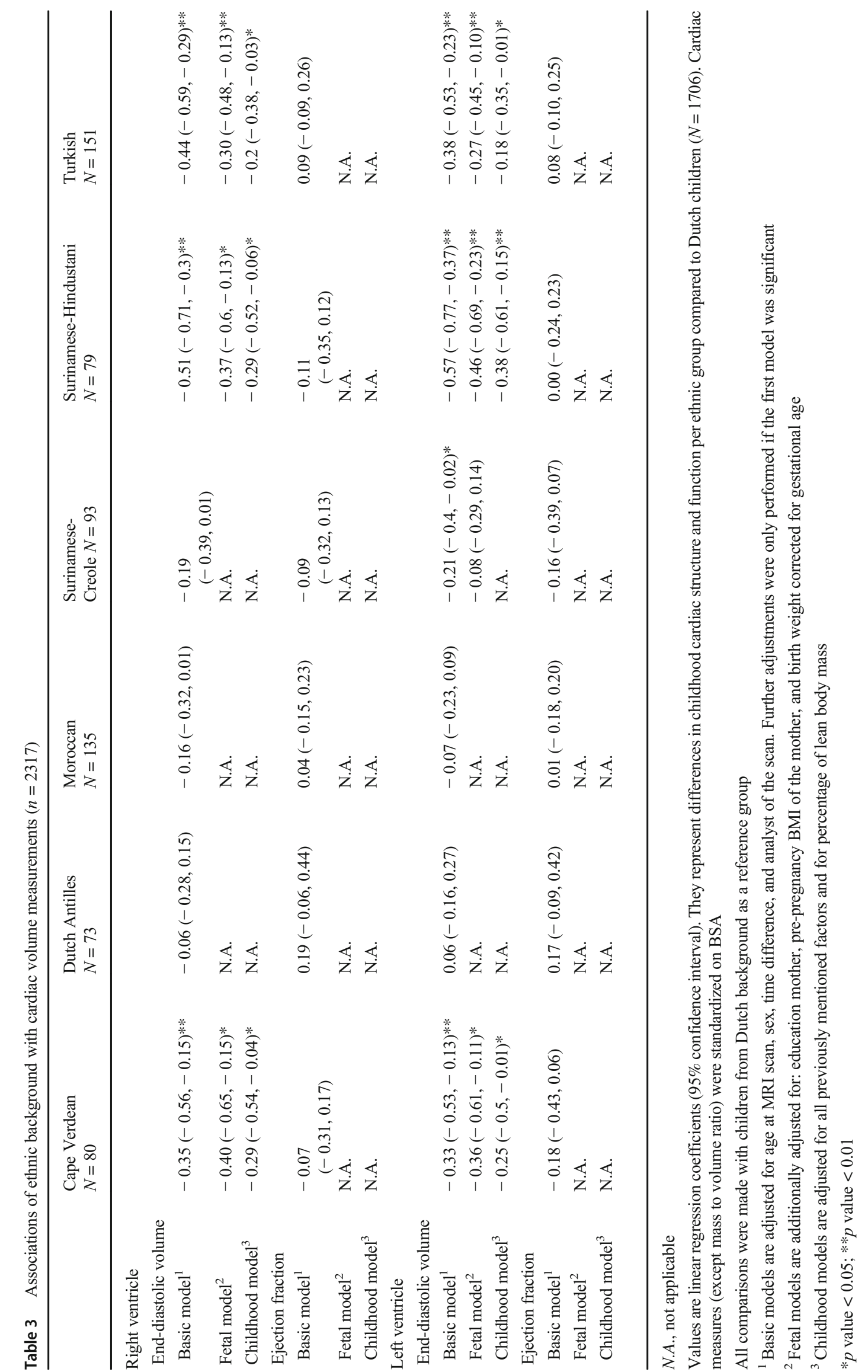




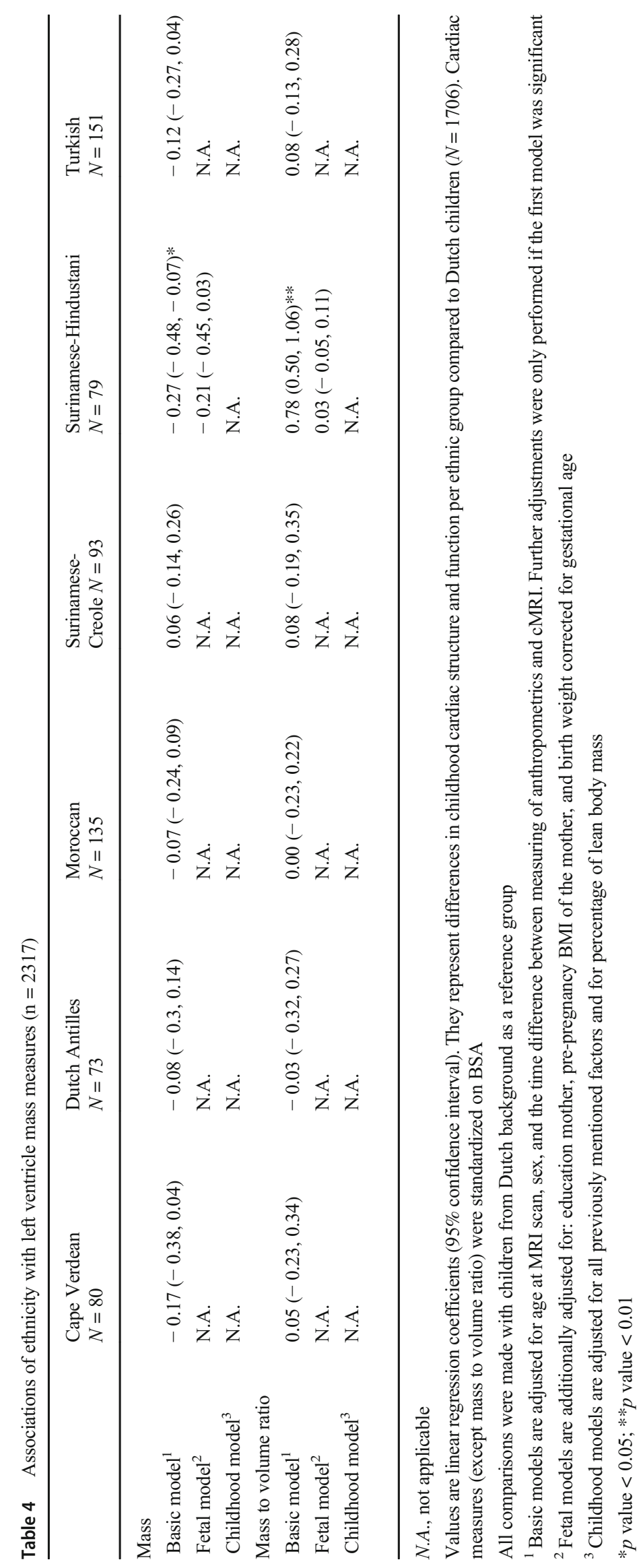


[31]. In the current study, we do not have detailed information on cardiovascular fitness and overall physical activity available, and we were not able to examine if differences in fitness could explain the associations of ethnicity with cardiac structure.

In adults a larger heart and higher LVM as well as RVEDV and LVEDV, are generally associated with higher risk of cardiovascular disease [12, 32]. A higher LMVR is associated with adverse cardiac outcomes, independent from LVM [33]. We observed a lower LVM and a higher LMVR in children from Surinamese-Hindustani background compared to Dutch children, but these associations attenuated fully after adjustment for fetal factors.

Our findings suggest that ethnicity is associated with cardiac structure at school-age, and this association is only partly explained by fetal and childhood factors. The differences we observed were small, and within normal ranges. Further studies are needed to explore whether these differences relate to adult cardiovascular disease. Multiple studies have established $Z$-scores for cardiac MRI. However, many of these studies are based on a relatively small study population. It would be interesting to create normal values in a large study population across all age-groups taking account for differences between ethnic subgroups.

To our knowledge, this is the first study focused on the associations of children's ethnicity with cardiac structure and function using cMRI in a large and diverse multiethnic prospective cohort. The major advantages of cMRI instead of echocardiography are more accurate measurements and information about the right cardiac structures [19]. Some limitations need to be considered. Of the original cohort, $60 \%$ of the children visited the research center at the age of 10 years. Of these children, $72 \%$ also attended the MRI center. Lower attendance is due to later start of the MRI study. cMRI was not performed in $15 \%$ of children that underwent body MRI. Reasons for not performing cMRI were often logistical, such as malfunctioning of equipment or time constraints. Also, we were not able to analyze $16 \%$ of the cMRI scans due to poor quality of the scans. This was partly due to using an 3.0T MRI scan, which is less ideal for imaging of the body [20,19]. Height and weight used to calculate BSA were measured during an earlier visit than the MRI scan. Around $65 \%$ of children visited the MRI within 2 months after the BSA visit, with a median time difference of 1.28 months $(95 \%$ range $(0,24.2)$ ). Even though we adjusted for the time difference, measurement error can cause attenuation of the observed associations. Finally, it is possible that the observed differences are explained by residual confounding. This could be due to specific factors such as physical activity, blood pressure and arterial hypertension, clustering of cardiovascular risk factors diet or possible comorbidities such as diabetes mellitus or chronic kidney disease (either diagnosed or subclinical), hyperlipidemia, or parental smoking exposure or other parental and childhood lifestyle characteristics [34, 35]. We previously reported ethnic differences in well-known cardiovascular risk factors [10]. Adjustment for these factors did not explain all ethnic differences in cardiovascular risk factors.

\section{Conclusions}

Right and left cardiac dimensions differ between ethnic groups in childhood. These differences are only partly explained by fetal and childhood factors. Further research is necessary to examine how ethnic differences in cardiac structure progress during and after adolescence, and if this contributes to later cardiovascular disease.

Acknowledgments We gratefully acknowledge the contribution of the participating children, their mothers, general practitioners, hospitals, midwives, and pharmacies in Rotterdam. The Generation R Study is conducted by the Erasmus Medical Center in close collaboration with the School of Law and Faculty of Social Sciences of the Erasmus University Rotterdam; the Municipal Health Service Rotterdam area, Rotterdam; the Rotterdam Homecare Foundation, Rotterdam; and the Stichting Trombosedienst and Artsenlaboratorium Rijnmond (STAR), Rotterdam.

Authors' contributions $\mathrm{LT}, \mathrm{AR}, \mathrm{MV}, \mathrm{RG}, \mathrm{WH}$, and VJ contributed to conception or design of the work. All authors contributed to acquisition, analysis, or interpretation of data for the work. WG, LT, and VJ drafted the manuscript, and all authors critically revised the manuscript and gave final approval.

Funding The Generation R Study is made possible by financial support from the Erasmus University Medical Centre, Rotterdam; the Erasmus University Rotterdam; and the Netherlands Organization for Health Research and Development. Romy Gaillard received a grant from the Dutch Heart Foundation (grant number 2017T013). Vincent Jaddoe received a Consolidator Grant from the European Research Council (ERC2014-CoG-648916).

Data availability Data is available upon request from the principal investigator (Prof. Dr. Vincent Jaddoe)

\section{Compliance with ethical standards}

Conflict of interest The authors declare that they have no conflict of interest.

Ethics approval The study has been approved by the Medical Ethics Committee of the Erasmus University Medical Center, Rotterdam.

Consent to participate Written informed consent was obtained from all parents of participants.

Consent to publication Written informed consent was obtained from all parents of participants.

Code availability All analyses were done in R 3.6.1 and multiple imputations were done using the MICE package. 
Open Access This article is licensed under a Creative Commons Attribution 4.0 International License, which permits use, sharing, adaptation, distribution and reproduction in any medium or format, as long as you give appropriate credit to the original author(s) and the source, provide a link to the Creative Commons licence, and indicate if changes were made. The images or other third party material in this article are included in the article's Creative Commons licence, unless indicated otherwise in a credit line to the material. If material is not included in the article's Creative Commons licence and your intended use is not permitted by statutory regulation or exceeds the permitted use, you will need to obtain permission directly from the copyright holder. To view a copy of this licence, visit http://creativecommons.org/licenses/by/4.0/.

\section{References}

1. Goff DC, Nichaman MZ, Chan W, Ramsey DJ, Labarthe DR, Ortiz C (1997) Greater incidence of hospitalized myocardial infarction among Mexican Americans than non-Hispanic whites. The Corpus Christi Heart Project, 1988-1992. Circulation 95(6):1433-1440. https://doi.org/10.1161/01.cir.95.6.1433

2. Kautz JA, Bradshaw BS, Fonner E Jr (1981) Trends in cardiovascular mortality in Spanish-surnamed, other white, and black persons in Texas, 1970-1975. Circulation 64(4):730-735. https://doi. org/10.1161/01.cir.64.4.730

3. Bhopal RS, Humphry RW, Fischbacher CM (2013) Changes in cardiovascular risk factors in relation to increasing ethnic inequalities in cardiovascular mortality: comparison of cross-sectional data in the Health Surveys for England 1999 and 2004. BMJ Open 3(9): e003485. https://doi.org/10.1136/bmjopen-2013-003485

4. Wild SH, Fischbacher C, Brock A, Griffiths C, Bhopal R (2007) Mortality from all causes and circulatory disease by country of birth in England and Wales 2001-2003. J Public Health 29(2):191-198. https://doi.org/10.1093/pubmed/fdm010

5. Bos V, Kunst AE, Keij-Deerenberg IM, Garssen J, Mackenbach JP (2004) Ethnic inequalities in age- and cause-specific mortality in The Netherlands. Int J Epidemiol 33(5):1112-1119. https://doi.org/ 10.1093/ije/dyh189

6. Baauw A, Ritz N (2018) Towards better healthcare for migrant and refugee children in Europe. Eur J Pediatr 177(2):161-162. https:// doi.org/10.1007/s00431-017-3019-4

7. Schrier L, Wyder C, Del Torso S, Stiris T, Von Both U, Brandenberger J, Ritz N (2019) Medical care for migrant children in Europe: a practical recommendation for first and follow-up appointments. Eur J Pediatr 178(9):1449-1467. https://doi.org/10. 1007/s00431-019-03405-9

8. Chen X, Wang Y (2008) Tracking of blood pressure from childhood to adulthood: a systematic review and meta-regression analysis. Circulation 117(25):3171-3180. https://doi.org/10.1161/ CIRCULATIONAHA.107.730366

9. Joshi SM, Katre PA, Kumaran K, Joglekar C, Osmond C, Bhat DS, Lubree H, Pandit A, Yajnik CS, Fall CH (2014) Tracking of cardiovascular risk factors from childhood to young adulthood - the Pune Children's Study. Int J Cardiol 175(1):176-178. https://doi. org/10.1016/j.ijcard.2014.04.105

10. Gishti O, Gaillard R, Felix JF, Bouthoorn S, Steegers E, Raat H, Hofman A, Duijts L, Franco OH, Jaddoe VW (2015) Early origins of ethnic disparities in cardiovascular risk factors. Prev Med 76:84 91. https://doi.org/10.1016/j.ypmed.2015.03.027

11. Winkleby MA, Robinson TN, Sundquist J, Kraemer HC (1999) Ethnic variation in cardiovascular disease risk factors among children and young adults: findings from the Third National Health and
Nutrition Examination Survey, 1988-1994. JAMA 281(11):10061013. https://doi.org/10.1001/jama.281.11.1006

12. Levy D, Garrison RJ, Savage DD, Kannel WB, Castelli WP (1990) Prognostic implications of echocardiographically determined left ventricular mass in the Framingham Heart Study. N Engl J Med 322(22):1561-1566. https://doi.org/10.1056/ NEJM199005313222203

13. Urbina EM, Gidding SS, Bao W, Pickoff AS, Berdusis K, Berenson GS (1995) Effect of body size, ponderosity, and blood pressure on left ventricular growth in children and young adults in the Bogalusa Heart Study. Circulation 91(9):2400-2406. https://doi.org/10.1161/ 01.cir.91.9.2400

14. Kishi S, Reis JP, Venkatesh BA, Gidding SS, Armstrong AC, Jacobs DR Jr, Sidney S, Wu CO, Cook NL, Lewis CE, Schreiner PJ, Isogawa A, Liu K, Lima JA (2015) Race-ethnic and sex differences in left ventricular structure and function: the Coronary Artery Risk Development in Young Adults (CARDIA) Study. J Am Heart Assoc 4(3):e001264. https://doi.org/10.1161/JAHA.114.001264

15. Chahal NS, Lim TK, Jain P, Chambers JC, Kooner JS, Senior R (2010) Ethnicity-related differences in left ventricular function, structure and geometry: a population study of UK Indian Asian and European white subjects. Heart 96(6):466-471. https://doi. org/10.1136/hrt.2009.173153

16. Dekkers C, Treiber FA, Kapuku G, Van Den Oord EJ, Snieder H (2002) Growth of left ventricular mass in African American and European American youth. Hypertension 39(5):943-951. https:// doi.org/10.1161/01.hyp.0000015612.73413.91

17. Schieken RM, Schwartz PF, Goble MM (1998) Tracking of left ventricular mass in children: race and sex comparisons: the $\mathrm{MCV}$ Twin Study. Medical College of Virginia. Circulation 97(19): 1901-1906. https://doi.org/10.1161/01.cir.97.19.1901

18. Daniels SR, Kimball TR, Morrison JA, Khoury P, Witt S, Meyer RA (1995) Effect of lean body mass, fat mass, blood pressure, and sexual maturation on left ventricular mass in children and adolescents. Statistical, biological, and clinical significance. Circulation 92(11):3249-3254. https://doi.org/10.1161/01.cir.92.11.3249

19. Gardner BI, Bingham SE, Allen MR, Blatter DD, Anderson JL (2009) Cardiac magnetic resonance versus transthoracic echocardiography for the assessment of cardiac volumes and regional function after myocardial infarction: an intrasubject comparison using simultaneous intrasubject recordings. Cardiovasc Ultrasound 7:38. https://doi.org/10.1186/1476-7120-7-38

20. Helbing WA, Bosch HG, Maliepaard C, Rebergen SA, van der Geest RJ, Hansen B, Ottenkamp J, Reiber JH, de Roos A (1995) Comparison of echocardiographic methods with magnetic resonance imaging for assessment of right ventricular function in children. Am J Cardiol 76(8):589-594. https://doi.org/10.1016/s00029149(99)80161-1

21. Kawut SM, Barr RG, Lima JA, Praestgaard A, Johnson WC, Chahal H, Ogunyankin KO, Bristow MR, Kizer JR, Tandri H, Bluemke DA (2012) Right ventricular structure is associated with the risk of heart failure and cardiovascular death: the Multi-Ethnic Study of Atherosclerosis (MESA)-right ventricle study. Circulation 126(14):1681-1688. https://doi.org/10.1161/ CIRCULATIONAHA.112.095216

22. Jaddoe VW, van Duijn CM, Franco OH, van der Heijden AJ, van Iizendoorn MH, de Jongste JC, van der Lugt A, Mackenbach JP, Moll HA, Raat H, Rivadeneira F, Steegers EA, Tiemeier H, Uitterlinden AG, Verhulst FC, Hofman A (2012) The Generation R Study: design and cohort update 2012. Eur J Epidemiol 27(9): 739-756. https://doi.org/10.1007/s10654-012-9735-1

23. voor De Statistiek CB, en Leefsituatie DKS (2004) Allochtonen in Nederland. CBS,

24. Troe EJ, Raat H, Jaddoe VW, Hofman A, Looman CW, Moll HA, Steegers EA, Verhulst FC, Witteman JC, Mackenbach JP (2007) Explaining differences in birthweight between ethnic populations. 
The Generation R Study. BJOG 114(12):1557-1565. https://oi. org/10.1111/j.1471-0528.2007.01508.x

25. Toemen L, Gaillard R, Roest AA, van der Geest RJ, Steegers EA, van der Lugt A, Helbing WA, Jaddoe VW (2019) Fetal and infant growth patterns and left and right ventricular measures in childhood assessed by cardiac MRI. Eur J Prev Cardiol:2047487319866022. doi:https://doi.org/10.1177/2047487319866022

26. Lopez L, Colan SD, Frommelt PC, Ensing GJ, Kendall K, Younoszai AK, Lai WW, Geva T (2010) Recommendations for quantification methods during the performance of a pediatric echocardiogram: a report from the Pediatric Measurements Writing Group of the American Society of Echocardiography Pediatric and Congenital Heart Disease Council. J Am Soc Echocardiogr 23(5):465-495; quiz 576-467. https://doi.org/10.1016/j.echo. 2010.03.019

27. Team RC (2015) R: a language and environment for statistical computing. Vienna, Austria: R Foundation for Statistical Computing; 2014. R Foundation for Statistical Computing. ISBN 3-900051-07-0. http:// www. R-project. org,

28. Rigby RA, Stasinopoulos DM (2005) Generalized additive models for location, scale and shape. J R Stat Soc: Ser C: Appl Stat 54(3): 507-554. https://doi.org/10.1111/j.1467-9876.2005.00510.x

29. Buuren S, Groothuis-Oudshoorn K (2011) mice: multivariate imputation by chained equations in R. J Stat Softw 45(3). https://doi. org/10.18637/jss.v045.i03

30. Dijkshoorn H, Uitenbroek DG, Middelkoop BJ (2003) Prevalence of diabetes mellitus and cardiovascular disease among immigrants from Turkey and Morocco and the indigenous Dutch population.
Ned Tijdschr Geneeskd 147(28):1362-1366. https://doi.org/10. 1161/01.hyp.0000015612.73413.91

31. Maron BJ, Pelliccia A (2006) The heart of trained athletes: cardiac remodeling and the risks of sports, including sudden death. Circulation 114(15):1633-1644. https://doi.org/10.1161/ CIRCULATIONAHA.106.613562

32. Haider AW, Larson MG, Benjamin EJ, Levy D (1998) Increased left ventricular mass and hypertrophy are associated with increased risk for sudden death. J Am Coll Cardiol 32(5):1454-1459. https:// doi.org/10.1016/s0735-1097(98)00407-0

33. Bluemke DA, Kronmal RA, Lima JA, Liu K, Olson J, Burke GL, Folsom AR (2008) The relationship of left ventricular mass and geometry to incident cardiovascular events: the MESA (MultiEthnic Study of Atherosclerosis) study. J Am Coll Cardiol 52(25): 2148-2155. https://doi.org/10.1016/j.jacc.2008.09.014

34. Sharma P, Middelberg RP, Andrew T, Johnson MR, Christley H, Brown MJ (2006) Heritability of left ventricular mass in a large cohort of twins. J Hypertens 24(2):321-324. https://doi.org/10. 1097/01.hjh.0000202815.18083.03

35. Post WS, Larson MG, Myers RH, Galderisi M, Levy D (1997) Heritability of left ventricular mass: the Framingham Heart Study. Hypertension 30(5):1025-1028. https://doi.org/10.1161/01.hyp.30. 5.1025

Publisher's note Springer Nature remains neutral with regard to jurisdictional claims in published maps and institutional affiliations.

\section{Affiliations}

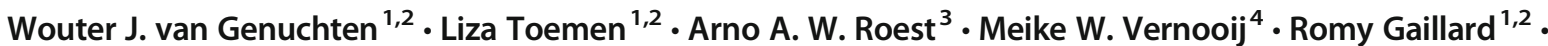 Willem A. Helbing ${ }^{2}$. Vincent W. V. Jaddoe ${ }^{1,2}$}

1 The Generation R Study Group (Na 2915), Erasmus MC, University Medical Center, PO Box 2040, 3000 CA Rotterdam, the Netherlands

2 Department of Pediatrics, Erasmus MC, University Medical Center, Rotterdam, the Netherlands
3 Department of Pediatrics, Leiden University Medical Center, Leiden, the Netherlands

4 Department of Radiology \& Nuclear Medicine, Erasmus MC, University Medical Center, Rotterdam, the Netherlands 